\title{
VIRGEM SENHORA NOSSA MÃE PARADOXAL
}

\author{
Virgin Lady Our Mother Paradoxal
}

\author{
Paola Basso Menna Barreto Gomes Zordan*
}

\begin{abstract}
RESUMO
Figuras femininas, em especial a Virgem Maria, apresentam aspectos icônicos e mitológicos propícios para se pensar como a mulher é vista, sentida e prospectada. Características da figura são tratadas com a semiologia de Barthes para desenvolver uma crítica junto as invaginações e o pensamento genital de Gilles Deleuze. Com a mitologia semiológica aborda a popularização de sua imagem de culto na contexto do final do século XIX a fim de mostrar criações poética e críticas e através de amostras do paradoxo inerente à imagem. A intenção é construir outros modos de pensar o feminino para problematizar as diferentes séries de sentido que convergem na figura de Nossa Senhora. As imagens em evidência neste texto dão origens a produções sincréticas, onde as relações entre signos sacros e sexuais se imiscuem, evidenciando paradoxos de sentido na devoção mariana.
\end{abstract}

Palavras-chave: Virgem Maria; figura; feminino; invaginação

\begin{abstract}
Female figures like the Virgin Mary presentes mythological and iconical aspects appropriate to think as woman's prospect, in sense and sight. Figure characteristics are treated with Barthes to intent make a brief criticism with invaginations and genital thought of Gilles Deleuze. With semiological mythology addresses the popularization of her devotion workship that comes from the late nineteenth century to for display poetic and critical creations through some samples from image paradoxes. The goal is demonstrate how to build a way of thinking the feminine which

* Doutora e Mestre em Educação, Bacharel em Desenho e Licenciada em Educação Artística pela Universidade Federal do Rio Grande do Sul. Professora do Departamento de Artes Visuais da Universidade Federal do Rio Grande do Sul, pesquisa historiografia e epistemologia das artes. Na mesma instituição é professora do Programa de Pós-graduação em Educação na linha de
\end{abstract} pesquisa Filosofias da Diferença. 
asserts itself for problematize the different series of sense that converge in the Our Lady figure. The images in evidence this text generate syncretic productions, where the relationship between sacred and sexual signs are blended, showing sense of paradoxes in the marian cult.

Keywords: Virgin Mary; figure; feminin; intussusception

\section{Figura 1}

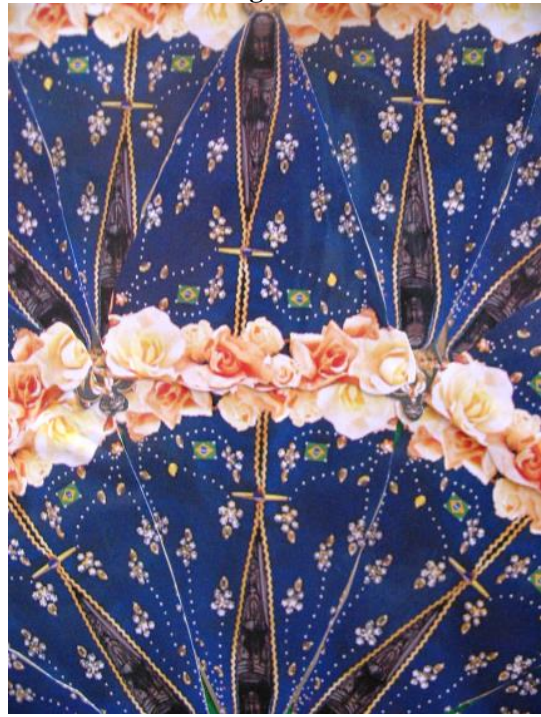

Projeto Idolatria Iconoclasta, Mandala Aparecida (detalhe), colagem, 2005

\section{Gratia plena}

Um poema da juventude de Oscar Wilde ${ }^{1}$, fruindo de obras de arte em uma viagem para Itália, em 1881, mostra o paroxismo em

1 Ave Maria Gratia Plena. Disponível em: http://www.literaturecollection.com/a/wilde/344, acesso em março de 2015 . 
que o culto ao feminino sagrado, típico da Era Vitoriana em que viveu, se mistura a insinuações de desejo sexual, configurando uma idolatria ao corpo com aspectos de adoração sacra. Maria que "concebe sem pecado" aparece tal qual as amantes de Zeus, Danae e Semele $^{2}$. Nos paradoxos expostos na vida desse escritor irlandês, Bachelor of Fine Arts em Oxford ${ }^{3}$, dogmas, preconceitos e mitificações nos dias de hoje ainda podem ser sentidos. No tempo vivido por Oscar Wilde perfumado pelas Flores (1861) de Baudelaire, do "hospital, lupanar e purgatório", Nietzsche critica os ideais de castidade nas óperas de Wagner, mostrando a "decadência" daquilo que até então era considerado cultura. Esse tempo de consumo de literatura "gótica". Período de propagação dos dispositivos ópticos, quando a fotografia se populariza e surge o cinema, levando a pintura a se recriar enquanto expressão. A segunda metade do século XIX apresenta as condições de emergência da psicanálise e do materialismo dialético, cujas marcas reverberam nos modos de vida atuais, sendo que suas crises epistemológicas ainda hoje são sentidas. Com pinturas e outros tipos de ícones que retratam o feminino, especialmente aquelas mitificadas em figuras de tradição secular, rupturas e continuidades formais mostram como, hoje, o passado nos subjetiva. Modos de figurar a mulher desde um período arcaico, atravessando os séculos medievos, passando pelo Renascimento e os classicismos que o procedem, chegam na Belle Époque, final do século XIX e início do século XX, dentro de um prospecto paradoxal se extrema relevância para as lutas das mulheres na atualidade. Observando aquilo que encantou e inspirou Wilde, o entusiasmo por um tipo de força inspiradora que o poeta expressou como a mulher, a mãe, o receptáculo do divino, corpo imaculado, claro em sua luz, purificado pelo fogo, carne em ascensão, oferecida a Deus, nos deparamos com estudos sobre Histeria e místicas em torno da virgindade. Nesse contexto emergem os paradoxos mais contundentes das figurações femininas, mulheres começam a questionar seus direitos no mesmo compasso que cultos populares, com base em

2 WILDE, Oscar. Obra completa. Trad. Oscar Mendes. Rio de Janeiro: Nova Aguillar, 1980.

3 SCHIFFER, Daniel Salvatore. Oscar Wilde. Trad. Joana Cañedo. Porto Alegre: LP\&M, 2010.

4 BAUDELAIRE, Charles. Les Fleurs du Mal. Gallimard, 1996, p. 238. 
aparições de Nossa Senhora, se expandem. Em relativas aproximações e distanciamentos desse referencial com a vida diversificada do amplo território do Brasil, pode-se enumerar as figurações de feminino a partir de um elemento que reúne distintos povos brasileiros, desde os que vivem no calor da Amazônia até os que sobreviveram aos ventos gélidos do Pampa: o culto à Virgem Mãe.

Tal culto envolve a relação com imagens, sendo essa relação aqui pensada. Que tipo de culto implica a relação com uma série de imagens reproduzidas de forma variada para representar um ente que ama, protege, consola, provê? Sempre virtualmente, visto não existir como "ser" atuante, apenas como atualização de uma força que opera entre a figura cultuada e a quem ela se devota. As produções de feminino desde o século XII até o século XIX eram prioritariamente variações dos temas marianos descritos nas 15 cenas dos Mistérios do Rosário. Na pintura e suas reproduções persistem alguns cânones de figuração que atravessam quatro séculos. Podemos traçar algumas analogias, como as feitas por Eugenio Garin, professor da Universidade de Florença, entre o Renascimento, com a emergência do período colonial, e a Bélle Époque, períodos que apresentam momentos de crise nas sistematizações filosóficas anteriormente estabelecidas. Relacionando os quadros aqui reproduzidos com as rupturas epistemológicas da segunda metade do século XIX, é possível visualizar a continuidade desse culto nas polissemias icônicas das apropriações artísticas. O presente texto não apresenta as variedades de incidências imagéticas das recriações contemporâneas em torno da imagem da Virgem Maria, sendo mostrada, como exemplo, apenas uma colagem com estampas de Nossa Senhora Aparecida (fig, 1 e fig. 6), criada em projeto poético anterior a elaboração da pesquisa iconográfica, da coleta de fontes que deriva em amplo arquivo de incidências e da crítica semiológica aqui desenvolvida.

A Virgem Maria é um dos ícones femininos abundantemente propagado na tradição artística e historiográfica do Ocidente. No presente estudo consideramos o movimento das imagens icônicas, de cunho representativo e narrativo, em direção ao que Deleuze, em seus 
estudos em torno da pintura, designa como Figura, ou seja, uma "forma sensível referida à sensação". Por figuração feminina temos alma mater, personificadora da matéria que sustenta a vida: Terra, fluxos, Anima, Nossa Senhora, Vênus. Seguindo as considerações de Roland Barthes, ao se procurar os signos que fornecem a "matérias primas da fala mítica" ${ }^{6}$ antes dessas produzirem seus significantes, temos a associação entre conceitos, imagens e atributos formais. Reiterando uma pesquisa que observa que "o culto de Maria foi mais proeminente e mais efetivo nos ícones"7, considera-se a diferenciação feita por Erwin Panofsky entre o estudo iconográfico dos atributos formais e os significados simbólicos implicados na análise iconológica, embora essa análise não proceda, conforme denotado no desenvolvimento do arquivo que aglutina as figuras levantadas pela pesquisa. Isto porque suas conotações simbólicas contradizem qualquer principio repetitivo e simples. Nenhuma interpretação analítica se apresenta segura, pois o sentido desse tipo de figura não é o que a forma atribuída denota. Numa perspectiva historiográfica temos o que Carlo Ginzburg traz em relação aos métodos indiciários que surgem nas pesquisas do Warburg Institute, as quais ajudam a simplificar os problemas semiológicos estudados com Barthes. Para este último uma figura "é uma configuração incivil, impessoal, acrônica, de relações simbólicas" que podem ser lidas em seus múltiplos e diversos sentidos ${ }^{8}$.

O historiador das religiões Jaroslav Pelikan, autor de Maria através dos séculos, observa que essa figura "proporcionou a definição de feminilidade" , sendo o papel da figura de Maria, dentro do cristianismo, o que permite o estabelecimento de elos "com outras tradições"10. Em seus estudos compreende que analisar "a história da espiritualidade e da devoção ocidentais", mais afetada pela vida diária

5 DELEUZE, Gilles. Francis Bacon: a lógica da sensação. Trad. Roberto Machado (coord.). Rio de Janeiro: Jorge Zahar, 2007, p.42).

6 BARTHES, Roland. Mitologias. Rio de Janeiro: Bertrand Brasil, 1993, p. 136.

7 PELIKAN, Jaroslav. Maria através dos séculos: seu papel na história da cultura. São Paulo: Cia das Letras, 2000, p. 140.

8 BARTHES, Roland. Mitologias. Rio de Janeiro: Bertrand Brasil, 1993, p.98.

9 PELIKAN, Jaroslav. Maria através dos séculos: seu papel na história da cultura. São Paulo: Cia das Letras, 2000, p.15.

10 PELIKAN, Jaroslav. Maria através dos séculos: seu papel na história da cultura. São Paulo: Cia das Letras, 2000, p. 99. 
e crenças populares, diferentes dos dogmas e dos credos encontrados na História da Igreja e na liturgia oficial, não é possível "sem levar em conta o lugar ocupado pela Virgem Maria"11. Entretanto, como "principal causa da divisão entre os crentes e Igrejas" da cristandade, há que se considerar as raras e poucas passagens que em que Maria aparece na Bíblia, sendo que é a partir de sua força que a autoridade das Escrituras pode ser questionada, visto seu culto reiterar "o desdobramento da doutrina pela tradição"12. A partir da leitura de Jaroslav é possível afirmar o quanto o marianismo visibiliza discursos que estruturam o pensamento contemporâneo sobre o feminino e construções históricas em torno da mulher. Tomar a iconografia mariana sincrética como corpo de estudos em torno dos processos de subjetivação femininos implica levantar as figuras femininas do final do século XIX, tanto nas suas referências precursoras quanto nas que as precedem, em suas múltiplas séries: as de Virgens (feminino ideal), as Vênus (feminino sensual) e esfinges (feminino monstruoso); trazendo figuras que apresentam polissemias plásticas e visuais em contraponto com a tradição iconográfica de herança branca, cristã e europeia que domina os referenciais em questão. As possibilidades de descrever processos de subjetivação femininos junto à figura da Virgem Maria são inúmeras, todavia, antes de análises minuciosas, apresenta-se uma síntese do tema perante seus principais esquemas semiológicos. Junto à Nietzsche, Foucault e Deleuze, por meio do estudo do conceito de dobra em suas bases diferenciais ${ }^{13}$ a figuração pode ser tratada como acontecimento, sendo cada incidência mote para criação de novos modos de vida. Na paisagem onde o peculiar marianismo contemporâneo vem emergir, final do século XIX, época em que viveram, cada um em seu espaço, Wilde, Nietzsche e Mallarmé, podemos "pintar" as polissemias nesse artigo sintetizadas. Essa "pintura" contextual tem a finalidade de mostrar fatores implicados na figura em questão, a saber: 1) o nascimento da crítica; 2) a decadência e a escatologia literária; 3) marianismo e ideais

11 PELIKAN, Jaroslav. Maria através dos séculos: seu papel na história da cultura. São Paulo: Cia das Letras, 2000, p.291.

12 PELIKAN, Jaroslav. Maria através dos séculos: seu papel na história da cultura. São Paulo: Cia das Letras, 2000, p.32.

13 DELEUZE, Gilles. A dobra: Leibniz e o barroco. Campinas: Papirus, 1991. 
educativos; 4) elaboração social dos papéis da mulher perante a exaltação da maternidade e da família, 5) fantasmagoria, aparições e cultos populares como reação ao cientificismo e avanços tecnológicos, 6) história da pintura e seu desenvolvimento técnico, 7) o simbolismo como movimento artístico fragmentado. Trata-se de uma analítica em aberto, não levada a cabo em sua totalidade neste ensaio onde a crítica sintagmática de um cânone implica a recriação visual do ícone.

\section{Mãe Preta: águas doces}

Embora seja uma estatueta de terracota e não uma pintura, Nossa Senhora Aparecida, originalmente Conceição, a quem desde os tempos coloniais atribuem milagres e cujo ícone pop se confunde com a imagem do próprio Brasil $^{14}$, é uma das imagens que não podemos deixar de mencionar, visto encarnar o paroxismo da veneração popular a uma santa negra, "embaixatriz especial para a vasta maioria da raça humana" 15 que não é branca, no seio de uma cultura escravagista. Seja como entidade adorada por multidões, seja como alvo de reações ${ }^{16}$, trata-se de uma figura a ser investigada em função dos elementos que compõem seu "universalismo" ". A intenção é não fechar as motivações da pesquisa e acontecimentos como Aparecida em justificativas simplórias de âmbito técnico, icônico e simbólico: preta porque o barro se incrustou de resíduos no fundo do rio, a

14 ALVAREZ, Rodrigo. Aparecida: a biografia da santa que perdeu a cabeça, ficou negra, foi roubada, cobiçada pelos políticos e conquistou o Brasil. São Paulo: Globo, 2014.

15 PELIKAN, Jaroslav. Maria através dos séculos: seu papel na história da cultura. São Paulo: Cia das Letras, 2000, p.47.

16 Como a do pastor Sérgio Von Helder, da Igreja Universal do Reino de Deus, em 12 de outubro (dia de Nossa Senhora Aparecida) em 1995, chutando a imagem da santa e dizendo "isso aqui não funciona" no programa $O$ despertar da $F e ́$, questionando a associação de deus com imagens "feias e desgraçadas", protestando contra o custo desse tipo de "boneco". A cena foi explorada pela Rede Globo, concorrente da emissora. Cf: https://www.youtube.com/watch?v=WPIoxanOkxI

17 BARTHES, Roland. Mitologias. Rio de Janeiro: Bertrand Brasil, 1993, p.174. 
possível policromia da estatueta se desgastou no tempo em que ficou submersa, há um número considerável de cultos à santas negras, as representações arcaicas da Grande Mãe são escuras. O feminino está ligado a grutas e outras concavidades cheias de sombra e a formas hiperbólicas (como a que emoldura Nossa Senhora de Guadalupe ${ }^{18}$, também conhecida como La morenita) ${ }^{19}$ proporcionando a relação entre o ícone da Virgem com símbolos ctônicos ancestrais.

No Brasil, a mitologia popular encontra um culto de pescadores que ganha poder em sua intrincada servilidade aos governantes em passagem pelo vale do Paraíba, o que pode ser averiguado com a visita do Imperador Pedro I. Com a devoção de sua neta, Isabel Cristina de Bragança e Bourbon, cuja assinatura a liga à abolição da escravatura, o local de peregrinação cresce a ponto de fazer existir uma cidade. A Princesa Isabel oferece à estatueta uma coroa de ouro cravejada de diamantes e rubis, hoje exposta no Museu Nossa Senhora Aparecida com outras oferendas desse porte, inclusive as rosas de ouro doadas por Papas como reconhecimento de distinção. Oficializado e sacramentado pela Igreja Católica Romana, hoje o local abriga o maior santuário mariano do mundo, com projeto de Benedito Calixto de Jesus Neto, descendente do pintor paulista homônimo do final do século XIX.

A partir dessas aproximações, formas de sincretismo expressas em figuras femininas permitem que se observe modos de cultuar imagens junto ao valor de mercado auferido paras as mesmas. Também se atesta a impossibilidade de se colocar um preço ao que é patrimônio público da coletividade e não apenas um rol de objetos específicos sob a guarda de uma organização. A Nossa Senhora da Conceição barroca, achada pelos pescadores de Guaratinguetá no rio Paraíba no início do século XVIII, não está a venda. Como costume,

18 A aparição de Nossa senhora em Guadalupe, em pleno século XVI, é o primeiro acontecimento a permitir análises sincréticas entre nativos indígenas e devoção cristã. Tanto essa como as aparições que ocorrem entre o século XIX e as primeiras décadas do século XX são tematizadas em pesquisas etnográficas que tratam dos cultos, das peregrinações e da devoção mariana como fenômeno social e histórico. Cf: STEIL, C.; MARIZ C.; REESINK M. (orgs.). Maria entre os Vivos: reflexões teóricas e etnográficas sobre aparições marianas no Brasil. Porto Alegre: UFRGS, 2003.

19 Para um levantamento visual da simbologia em torno das virgens negras, práticas devocionais, ex-votos e conferir: BOYER, Marie-France. O culto e imagem da Virgem: oferendas, ornamentos e festivais. São Paulo: Cosac \& Naif, 2000. 
foi descartada por pessoa desconhecida ao leito do rio, por ter quebrado a cabeça. Imagens de barro, imagens de gesso quebram fácil e seu destino é um enterro. O acaso sincrônico, achar o corpo, depois a cabeça, o milagre da aparição dos peixes (alimento necessário), o agradecimento em forma de festa para o Conde da capitania, as rezas coletivas, os prodígios, são elementos que reforçam "o objeto de posse infinita" que fixa o mito ${ }^{20}$.

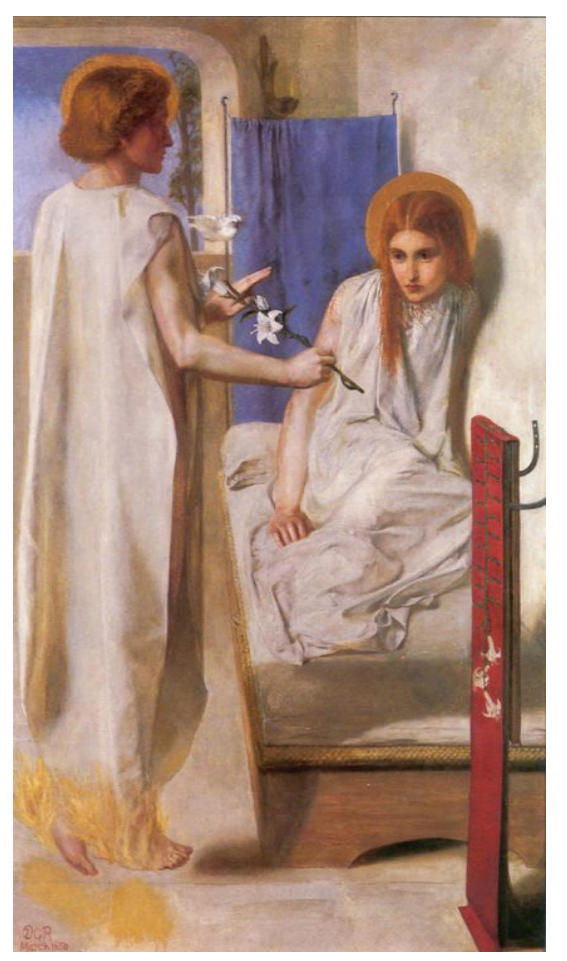

\section{Figura 2}

Dante Gabriel Rosseti, The Annunciation, 1850. Óleo sobre tela, $73 \mathrm{~cm} \times$ $41.9 \mathrm{~cm}$. Tate Britain Gallery. Disponível em: http://en.wikipedia.org/wi ki/Ecce Ancilla Domini, acesso acesso março 2015 


\section{Ecce Ancilla Domini}

Quando uma imagem se reduz a apenas sua forma, ensina Barthes que ela perde "parte de seu saber""21. Daí o mito sempre se afirmar enquanto fala significante que ganha sentido numa espécie de deformação, visto a forma, em si, nada dizer. Uma fala extremamente significativa no que se refere a construção do feminino como "modelo de inquestionada obediência" 22 pelo versículo "eis aqui a serva do Senhor" (Lc 1:26-38), proferida por Maria para o Arcanjo Gabriel no evangelho de São Lucas, configura a sintomática aqui tratada. Dante Gabriel Rosseti pinta uma Anunciação (fig.2) intitulada com esse dito, a qual apenas pelo lírio branco, marco iconográfico do tema ${ }^{23}$, presente na mão do anjo sem asas, podemos supor do que se trata. Uma Maria de feições pueris e boca cerrada recolhe seu corpo contra a parede perante as mãos da figura masculina que se aproxima. As roupas de ambas as figuras, assim como a roupa de cama e o lençol com o qual Maria se cobre, são brancas imitando linho. Seu manto azul, estendido na cabeceira do leito onde está sentada, parece um pano de fundo. Não fosse pela auréola das figuras, que retratam o irmão e a irmã do pintor, assim como o fogo dourado nos pés do "anjo", a cena não pareceria uma pintura religiosa, sendo a pequena pomba branca que irrompe pela janela elemento insuficiente para caracterizar a religiosidade do tema. Essa pintura pré-rafaelita permite outros modos de figurar o feminino e os temas sacros que a arte lhe impute. Maria, a "serva do Senhor", parece mais assustada do que resignada ao destino que o Arcanjo Gabriel lhe anuncia.

Sem esse tipo de ruptura que a segunda metade do século XIX contextualiza, um quadro como A origem do mundo (fig. 3), detalhe de um ventre feminino pela perspectiva dos genitais, pintado por Gustave Coubert em 1866, talvez fosse impossível. Pureza, castidade, servilidade e resignação se constelam no mito que se

21 BARTHES, Roland. Mitologias. Rio de Janeiro: Bertrand Brasil, 1993, p.141.

22 PELIKAN, Jaroslav. Maria através dos séculos: seu papel na história da cultura. São Paulo: Cia das Letras, 2000, p.119.

23 CASIMIRO, Luís A.E. Iconografia da Anunciação: símbolos e atributos. Ciências e Técnicas do Patrimônio. Porto, 2008-2009, série I, volume VII-VIII, pp.151-174. 
apresenta, não apenas junto ao seu dispositivo secular, que subjugou o feminino à moral dos patriarcados, mas principalmente naquilo que desmitifica a moralidade sobre qual as figurações, especialmente as marianas, se estruturam. Numa figuração plástica e imagética que associa figurações marianas a genitais femininos, ensaios anteriores, pensadas com Foucault, produziram arquivos de obras e análises sobre as imagens de vulva e o problema das representações plásticas e visuais no que tangem ao que é próprio do feminino ${ }^{24}$.

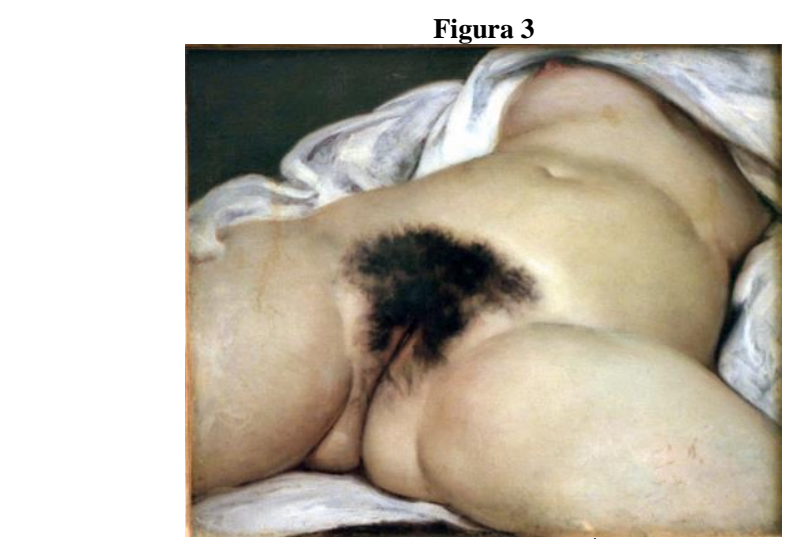

Gustave Coubert, L'Origine du monde, 1866 . Óleo sobre tela, $46 \mathrm{~cm} \times 55 \mathrm{~cm}$. Museu d'Orsay, Paris. Disponível em: http://pt.wikipedia.org/wiki/L\%27Origine_du_monde\#mediaviewer/File:Origin-of-the-World.jpg, acesso março 2015

Numa aproximação do pensamento estrutural de Barthes e a analítica territorial ao estilo de Foucault, Deleuze, Guattari, podemos tratar do mítico como aparelhamento do juízo moral exercido sobre o corpo, esse sempre suscetível aos discursos em torno de sua imagem. Mito é o que se fala, expõe Barthes, sendo o que se fala, ainda que numa forma, tomado como verdade. O que se escreve, escreve-se em

24 Cf. GOMES, P. B.M.B. Genitais Femininos e os Lugares da Diferença. In: FONSECA, T. M. G. e KIRST, P. G. (Orgs.) Cartografias e Devires: a construção do presente. Porto Alegre, Editora da UFRGS, 2003, p. 273-297 e ZORDAN, P.; MOMBACH, V. Corpo de passagem. 16o. Encontro Nacional da Associação Nacional de Pesquisa em Artes Plásticas. Florianópolis - SC. Dinâmicas epistemológicas em Artes Visuais. Florianópólis (SC), 2007. 
função de uma fala. A imagem, com seus indícios formais, exprime ditos. Nos termos de Foucault pode-se dizer que uma imagem expressa práticas discursivas, que aqui compõem diagramas submissos à temática e sua iconografia. Num plano conceptual, de plena substância, estruturas de pensamento que fazem do visível um sistema de concepções, sendo essas que dão formas para a vida.

Ao observar que os limites do mito são formais, não substanciais, a semiologia barthesiana traz o mito como operador de uma linguagem. Com Nietzsche e Deleuze, numa perspectiva em que toda linguagem é moral, procura-se uma nova abordagem do que Barthes trouxe como mitologia contemporânea. Essa considera compartimentos históricos e geográficos, mas agora dentro de uma semiótica particular, elaborada no devir da própria investigação junto aos demais autores que também fazem parte do referencial teórico. Com as lógicas deleuzianas, a do sentido ${ }^{25}$ e da sensação ${ }^{26}$, traça sua própria lógica do ícone, sendo aqui ícone uma palavra mais abrangente para tratar das figurações específicas a serem analisadas em outros estudos e no projeto poético intitulado idolatria iconoclasta, aqui demonstrado pela colagem de recortes de Nossa Senhora Aparecida em pequenos panfletos de oração. Numa era de profusão de imagens, hoje de alcance global, sendo essas imagens disseminadas em espaços coletivos, institucionais e comunitários, o que temos nas figuras elencadas para o estudo é a obstinação dos ícones: Nossa Senhora, a rosa, a flor, o anjo, o véu, os drapeados, as rugas, a pele, o seio, a lua, a aura, a serpente, a criança, a pomba, os genitais, traços animais. Rupturas e pertinências iconológicas que tornam uma Conceição, Aparecida. Nossa Senhora da Conceição é uma representação barroca da Virgem, sem véus e sem coroa, ladeada por inúmeros anjos, cuja iconografia amplamente disseminada nas estampas atuais provavelmente partem de uma série de pinturas datadas entre 1640 e 1680, atribuídas ao espanhol Bartolomé Esteban Murillo, as quais determinam o ícone reconhecido como Imaculada Conceição, sendo a pintura homônima de Victor Meirelles na Igreja

25 DELEUZE, Gilles. Lógica do sentido. São Paulo: Perspectiva, 2000.

26 DELEUZE, Gilles. Francis Bacon: a lógica da sensação. Trad. Roberto Machado (coord.). Rio de Janeiro: Jorge Zahar, 2007. 
matriz de Santo Antônio dos Anjos, na cidade de Laguna/SC, vinda de Roma em 1856, não disponível para reprodução, importante pista para estudos iconológicos aprofundados. Sejam figuras desviantes, como a pintura de Rossetti, ou iconograficamente referendadas a uma lógica icônica amplamente reproduzida, como a Imaculada Conceição, disponível para reprodução, do Museu do Prado (fig.4), todas são subjetivadoras na medida que criam as próprias figuras de seu Logos.

Figura 4

Bartolomé E.Murillo,

La Inmaculada de Soult, 1678 , Óleo sobre tela, $172 \times 285 \mathrm{~cm}$.

Museo Nacional del Prado.

Disponível em: http://upload.wikimedia.org /wikipedia/commons/6/61/ Murillo_immaculate_ conception.jpg

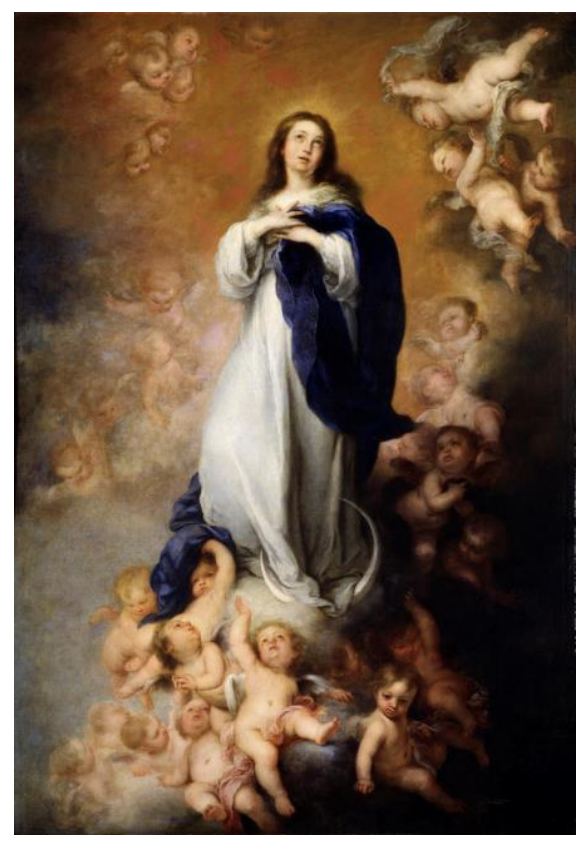

Jarolslav Pelikan observa que "entre as cenas da vida da Virgem Maria que despertaram a religiosidade dos devotos e a criatividade dos artistas, o tema predominante é a Anunciação, visto essa ser emblemática no que tange à tensão entre o livre-arbítrio humano e obrigação com a "soberania divina", a qual funciona como 
"modelo de paciência" e aceitação ${ }^{27}$. Da Assunção da Virgem (1516), pintura de Tiziano na igreja de Santa Maria Gloriosa dei Frari (fig.5) que encantou Oscar Wilde em Veneza, até as Nossas Senhoras dos cultos populares, temos, por formas de poder distintas, uma "superexploração da imagem da Virgem Maria"28. Há, nesse acontecimento que a autora compreende como "fenômeno", relações com o "sagrado" que não as sedimentadas sobre políticas propagadoras dos interesses de uma Igreja. Ao compreendermos como tais figuras se desviam do que os discursos canônicos a elas tentam colar, explorando o ciclo tradicional de Anunciação, Imaculada Concepção, Visitação, Fuga, Natividade, Maternidade, Dores, Morte (Pietá) e Ascenção, é possível abordar problemas relativos ao pensamento hermético implicado na elevação da carne em termos trágicos, poéticos e estéticos. Tal ciclo de cenas está intrincado com os enigmas da existência colocados por outras figuras que não apenas as de Virgem Maria, como as Vênus que perpassam a História da Arte e as Esfinges que abundam no contexto decadentista e simbolista em que a iconografia aqui referida se destaca. Entre a nudez e o excesso de roupagem, entre a figura humana canônica e monstruosidades, temos indícios de como cada tempo e cada local tratam, junto ao culto de imagens de divindades e divas femininas, etapas presentes na vida das mulheres. Junto aos métodos fragmentários da historiografia da vida privada ${ }^{29}$ aprendemos como as imagens produzem modos de vermos e concebermos a feminilidade. Junto a breve amostragem aqui levantada, a tensão entre a "heterogeneidade dos contextos" e a "homogeneidade morfológica" que, com as pesquisas de Carlo Ginzburg, atesta-se como a "convergência formal é histórica" ${ }^{30}$ e o quanto a particularidade dos documentos, a individualidade de cada caso e os indícios que

27 PELIKAN, Jaroslav. Maria através dos séculos: seu papel na história da cultura. São Paulo: Cia das Letras, 2000, p. 117-119.

28 REESINK, Mísia. Nossa Senhora de Angüera, Rainha da Paz e do mundo católico contemporâneo. In: STEIL, C.; MARIZ C.; REESINK M. (orgs.). Maria entre os Vivos: reflexões teóricas e etnográficas sobre aparições marianas no Brasil. Porto Alegre: UFRGS, 2003, p.89.

29 PERROT, Michelle. História da vida privada: da Revolução Francesa à Primeira Guerra. São Paulo: Companhia das Letras, 2009. 1989 , p. 183

30 GINZBURG, Carlo. Mitos, emblemas, sinais. São Paulo: Companhia das Letras, 
permitem reconstituir o que não obtemos simplesmente com a visão, ou seja, enigmas formais que não temos como resolver sem pesquisar ad infinitum.

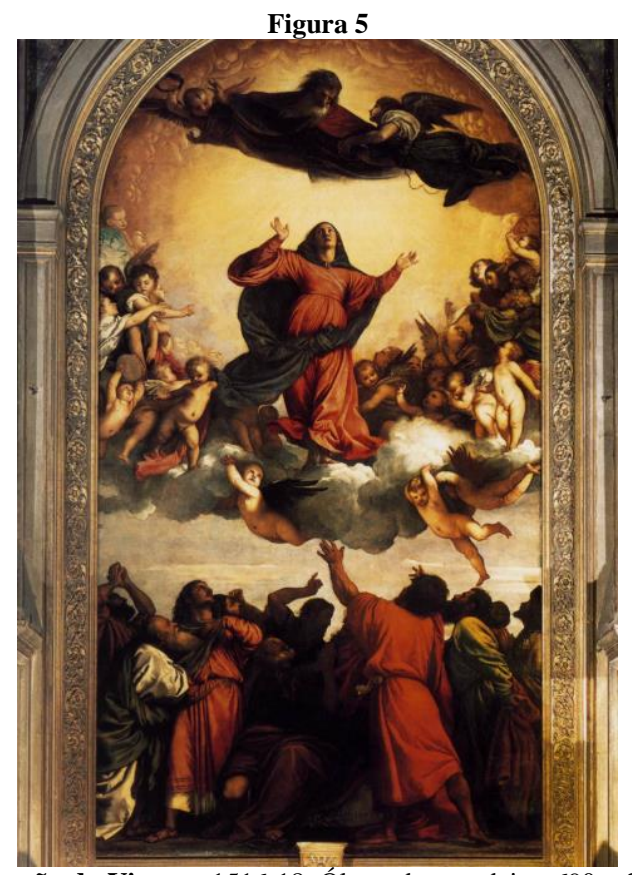

Tiziano, Assunção da Virgem, 1516-18. Óleo sobre madeira, 690 x $360 \mathrm{~cm}$. Santa Maria Gloriosa dei Frari, Veneza. Disponível em:

http://www.wga.hu/html_m/t/tiziano/01a/1assunt0.html, acesso março 2015.

\section{Hysterycus scenario}

Modos de vida estão impressos e são expressos nas imagens. O material icônico com o qual se produz arquivo, apresenta formas de expressão que lançam uma série de perguntas. Essas respondem a que 
signos estão em jogo nesse dispositivo dado a ver por figuras femininas. Quais signos em comum, quais permanências e rupturas iconográficas podem ser inventariadas, como apresentam indícios particulares, que fissuras nas tradições formais podem ser percebidas, entre outras questões que a observação de uma imagem, por si, levanta. Como fazer valer imagens de feminino que não as consagradas pela História e legitimadas pela historiografia da Arte, se não pela recriação que se apropria da iconografia consagrada? Figuras que, em sua expressão de formas variantes, disseminam relações de forças em que as dicotomias seculares de sacro e profano sejam transgressoras dentro do próprio sistema que as secularizou, diluindo forma e função em um só signo.

No ensaio, Feitiçaria e piedade popular, Carlo Ginzburg relata as confusões entre a Virgem Maria e o Demônio num processo inquisitorial do início do século XVI, na cidade de Modena ${ }^{31}$. Tanto o diabo quanto a virgem aparecem como figuras de consolo para os ressentimentos de uma camponesa desempregada. A série de signos que envolve as figuras da mulher, da serpente e do demônio cria o grande eixo temático que define a constituição do arquivo sincrético em que se debruça o pressente estudo e que, mesmo se detendo no final do século XIX, considera tradições orais intempestivas e imagens advindas do Renascimento e das Grandes Navegações. Para exemplificar, destaca-se a lenda que o escritor pelotense Simões Lopes Neto eterniza no texto A Salamanca do Jarau ${ }^{32}$. O folclore gaúcho tem como "mãe" de seu povo, criado em terra hostil, a figura da Teiuiniaguá. Essa princesa bruxa jovem e velha, tudo quase ao mesmo tempo, com corpo de lagarto, mas também linda mulher, mistura o imaginário guarani com a influência mourisca na colonização do Rio Grande do Sul. Em seu viés semiológico, a "substância de expressão" de uma imagem ${ }^{33}$, fora de uma significação constante, sem conseguir definir uma figura formalmente fixa, decompõe a significação. Problemas de continuidade (penetração e

31 GINZBURG, Carlo. História Noturna: decifrando o sabá. São Paulo: Companhia das Letras, 1991, p.15-39.

32 NETO, S. L. A Salamanca do Jarau. In: Contos gauchescos e lendas do sul. Porto Alegre: LP\&M, 2002.

33 BARTHES, Roland. Elementos de Semiologia. São Paulo: Cultrix, 1985, p.45. 
estratificação de sentido) se colocam em movimento com a ruptura que dissocia objetos de seu uso e padroniza o objeto na execução de um modelo. Os exemplos de imagens aqui elencados compreendem o phylum entre pinturas europeias clássicas (tradições iconográficas) e suas reproduções e recriações no Brasil. Relações de forças se apresentam nas adorações, obstinações e resistências em torno dessas figuras, enumerando casos em que energia e recursos são despendidos na conservação destas imagens e muitas atitudes em torno de estampas ou estatuetas tomadas como profanação ${ }^{34}$. Sem listar todas as ocorrências, é possível afirmar que as imagens femininas, tanto as marianas indeléveis quanto as variações sincréticas atribuídas ao demoníaco, trazem o "valor antropológico" 35 que representa a função de um signo. Porém pouco passível a interpretações fechadas, madonas, vaginas, mulheres e lagartas, destroem o discurso, complicam os termos da linguagem, abrem os textos à poética. $\mathrm{Na}$ disjunção entre a iconologia que define a temática aqui abordada com a perspectiva crítica assumida, temos a paisagem histórica que faz, com Baudelaire, que a vida moderna possa ser "pintada" e que a estética seja concebida como conhecimento não apenas estritamente textual. Época de Fausto, na qual Baudelaire e depois Nietzsche criticam a decadência, próspera de signos em torno do feminino, sendo o contraste entre santas e prostitutas acentuado no século XIX e início do século XX. Liberta de preceitos idealistas a ponto de produzir estéticas singulares como a de Baudelaire, esse decadentismo expressa escritos fundamentais para o pensamento contemporâneo. Pressuponho que o nascimento desse tipo de crítica não possa ser separado das variações iconológicas, epistêmicas e poéticas, procede-se pela "analogia universal" baudelairiana ${ }^{36}$, como é possível encontrar na leitura de $O$ pintor da vida moderna, publicado em 1863 no jornal Figaro sobre os croquis de Constantin Guys. Estéticas como a de Stéphane Mallarmé, na França e a de

34 ALVAREZ, Rodrigo. Aparecida: a biografia da santa que perdeu a cabeça, ficou negra, foi roubada, cobiçada pelos políticos e conquistou o Brasil. São Paulo: Globo, 2014. . Maria: A biografia da mulher que gerou o homem mais importante da história, viveu num inferno, dividiu os cristãos, conquistou meio mundo e é chamada Mãe de Deus. São Paulo: Globo, 2015.

35 BARTHES, Roland. Elementos de Semiologia. São Paulo: Cultrix, 1985, p.45.

36 DUFILHO, Jérôme. O pintor e o poeta. In: BAUDELAIRE. O Pintor da vida moderna. Organização e concepção de Jérôme Dufilho e Tomaz Tadeu. Belo Horizonte: Autêntica, 2010. 
Oscar Wilde, na Inglaterra e também em França, criam novos modo de se viver o feminino, inclusive nos homens, como vemos no dandismo de Baudelaire.

\section{Benetictus fructus ventris}

Mesmo limitando o estudo à contracultura que insurge quando nasce a crítica de artes tal como hoje pode ser pensada, elementos do Barroco também são considerados para se compreender de que modo os ícones da cultura vigente indicam novos modos de acepção visual junto a imagens seculares. Nos indícios destacados na superfície bidimensional de uma pintura, a partir as generalizações iconográficas e contextos sobre os quais formas e pensamentos se modificam, podemos ver a paisagem de outro tempo, como sua sociedade difere do nosso tempo, mas o quanto seus valores e moralidades ainda são mantidos. Ao observamos obras de diversos tipos e importância, pensamos por figuras, esteticamente, por sensações. Sua persistência as torna ícones, suas insistentes aparições as fazem mito, seus nomes criam temáticas: as figuras parecem estruturais, mas há nelas forças que extrapolam as próprias formas. Nas relações de forças as figuras compõem crenças, valores, apelos, sentimentos e toda uma teia de significações e delineamentos plásticos que quebram com os significados morais. Nas figuras da Virgem há signos que envolvem drapeados, dobras, invaginações, linhas hiperbólicas que mostram mais um diagrama maleável do que uma estrutura onde variáveis de tempo e espaço com certa facilidade sejam referendados.

Por isso, aqui interessam mais os signos "menores" do que a sequencialidade formal passível de ser encontrada em um ícone. Quando despidas de sua carga iconológica, quando carnificação pura, como Deleuze demonstra na pintura de Francis Bacon, as figuras testemunham sua própria impossibilidade de figurar um corpo, sendo a própria figura não mais que uma forma para dar corpo a um conceito. Se "as figuras tendem para conceitos a ponto de se 
aproximar infinitamente deles" ${ }^{37}$ sua ação, produtora de discursos, se afasta do sentido dado pela linguagem, tornando a figura imagem de sua própria expressão.

São evidências do quão paradoxal e complexo pode ser o culto mariano. Entre uma diversidade de questões, destaco sua ligação à tendências neo-pagãs de adoração à divindades femininas, a dogmatização católica em torno da pureza e do nascimento virginal e ainda a abominação do marianismo pelos evangélicos pentecostais. Esse corpus possibilita dialogar com pesquisas que tratam de representações icônicas da mulher e que mostram de que formas a mitologia erudita do ocidente concebe substancialmente como alma mater. Resgatando o sentido original da denominação pessoal virgem, encontramos na virgo dos antigos povos mulheres não submissas aos homens, trabalhadoras em templos, servidoras do povo, senhoras de si. Uma virgem esposa foge a os papéis socialmente dados ao feminino, misturando a Mãe, Princípio da raça, mulher envolvida com um homem, com a sacerdotisa, a mulher sozinha, guardiã de mistérios. Seja nas emblemáticas Ânimas, nas pictóricas Madonnas ou na simbolista Fêmme Fatale, esse conjunto configura um phatosphormen ocidental, conforme os estudos de Aby Warburg. Atribuições fantasiosas expressam imagens recorrentes. Ao se mostrar como se constitui o senso comum sobre o assunto, as explicações demasiado lineares, as causas e as consequências da paisagem e da história em relação ao feminino, se desconstroem associações correntes, como as que ligam a Anima Mundi, a Sophia dos gnósticos e Nossa Senhora com e o nascimento e os mitos de origem $^{38}$. O mito de que Maria sobe aos céus em carne, com seu corpo material, fornece importante pistas do paganismo que seu culto nunca deixou morrer. Oficializado pela constituição apostólica de Pio XII, em 1950, assim como o dogma da Conceição, reitera vários estudos que atestam o quanto a Igreja necessita legitimar crenças apócrifas que envolvem festas populares e outros tipos de veneração.

37 DELEUZE, Gilles e GUATTARI, Félix. O que é a filosofia? Rio de Janeiro: Ed. 34, 1992, p.121.

38 REESINK, Mísia. Nossa Senhora de Angüera, Rainha da Paz e do mundo católico contemporâneo. In: STEIL, C.; MARIZ C.; REESINK M. (orgs.). Maria entre os Vivos: reflexões teóricas e etnográficas sobre aparições marianas no Brasil. Porto Alegre: UFRGS, 2003, p.129. 
Essa desconstrução toma séries de sentido para mostrar como mitos de ascensão da carne e a própria liturgia do corpo na doutrina cristã, como a presente no dogma da Assunção, paradoxalmente afirmam uma perspectiva imanente dentro de um discurso que tenta estabelecer a transcendência. Com os estetas do século XIX, ao fulminar representações e identificações clássicas, carregadas de idealizações transcendentes, injetamos sangue e carne na imagem que a crença, em sua ingenuidade, malograria. Essa que é tanto Virgem como Mãe, tanto humana como divina, quiçá advinda da História como de estórias míticas, "Nossa Senhora dos Paradoxos"39, permite que o historiador das religiões observe que "ela figurava com maior proeminência fora da liturgia pública oficial que dentro dela"40, mostrando que mesmo a imagem de castidade e virtude varia constantemente, se dobrando a signos do feminino maiores dos que os imputados pelas religiões oficiais.

Sendo as imagens "mais imperativas que as palavras" 41 , trazer as descontinuidades em torno de uma figuração, como a de Nossa Senhora, possibilita que novos valores sejam criados a fim de que a vida não se subsuma à moral que determinadas imagens se dispõem a propagar. Aspectos que descrevem a tensão entre o sacro e o profano, como o estudo da histeria ${ }^{42}$, envolvem a produção intelectual e moral social situada no século XIX, período histórico em que o marianismo se torna uma devoção popular. Ao pesquisar constructos simbólicos em torno de imagens nas quais figuram mitos femininos, desmistifica-se o aspecto moral que perpassa a mitologia em torno da santa, da puta, da virgem que pode ser inclusive as duas, conforme podemos observar na vasta bibliografia sobre essa sobreposição $^{43}$. A propagação de imagens que se apresentam como marianismo sincrético de apropriação de referências da cultura

39 PELIKAN, Jaroslav. Maria através dos séculos: seu papel na história da cultura. São Paulo: Cia das Letras, 2000, p.77.

40 PELIKAN, Jaroslav. Maria através dos séculos: seu papel na história da cultura. São Paulo: Cia das Letras, 2000, p.138.

41 BARTHES, Roland. Mitologias. Rio de Janeiro: Bertrand Brasil, 1993, p.132.

42 DIDI-HUBERMANN, Georges. A invenção da histeria. Rio de Janeiro: Contraponto, 2015.

43 BARROS, Maria Nazareth Alvim de. As deusas, as bruxas e a Igreja: séculos de perseguição. Rio de Janeiro: Record, 2001. 
popular e de até de ícones midiáticos, juntamente com arquivos visuais catalogados junto à tradição, fornece indícios de como concepções de feminino se articulam aos signos aos quais a iconografia lhe devota. Mostrar a figura servil, maternal, confortadora e cheia de sofrimento, dada historicamente como ideal feminino de suprema dignidade a ser seguido na vida das mulheres, descreve como opera essa figuração e como o modo de vida que uma imagem produz se fazem valer. Na descrição de como funciona o discurso que uma imagem reforça, aqui em contrabalança da virgem com o feminino genital e animalesco, se colocando em evidência o nonsense do mito. Uma vez expressando o paradoxo entre séries de sentido divergentes, o sintagma mítico perde sua eficácia, deixando a mostra o sentido irracional da imagem cultuada, seja como "modelo", seja como mote para expiações morais. Desdobramentos do que aqui se apresenta conduzem a estudos pormenorizados em torno das produções que rompem com sistemas sintagmáticos canônicos, datadas na segunda metade do século XIX, tais como a patafísica e as obras de Qorpo Santo. Por seus avanços técnicos e bases de um modo de vida que hoje podemos dizer como da imagem, os sistemas críticos de pensamento dessa época, assim como a prática cotidiana de leitura e consumo de romances, são de extrema relevância na maneira de se pensar o tema do feminino sob a égide variável do marianismo. Nos sistemas de figuração do feminino, em face a estética que se estabelece desde o século XIX, vários aspectos da educação, das estruturas de pensamento e do gosto erudito e/ou popular podem ser analisados via uma crítica do contemporâneo. 


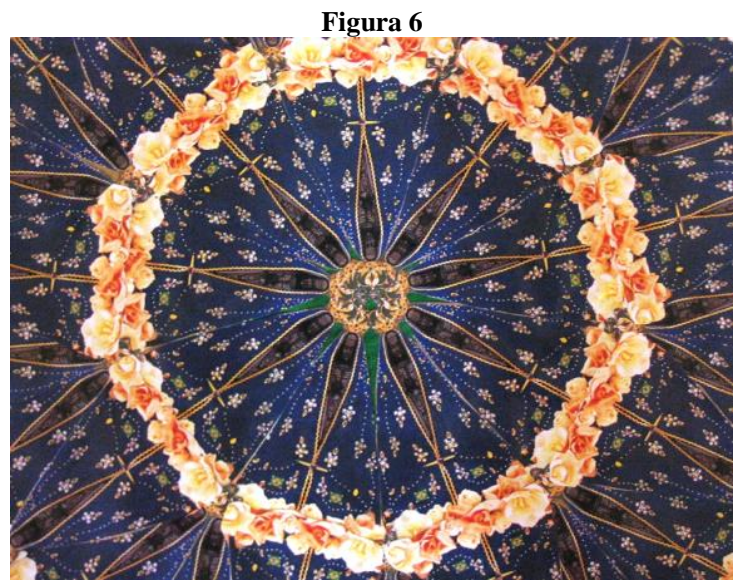

Projeto Idolatria Iconoclasta, Mandala Aparecida (centro), colagem, 54 x $54 \mathrm{~cm}$, 2005.

\section{Verbo caro factum est}

A crítica literária barthesiana nos apresenta figuras em termos de simulações romanescas; figuras cujo sentido original, uma vez textualizado, não pode ser recuperado em sua totalidade. Isso vai de encontro ao dinamismo que permeia as figuras que Deleuze, junto com pensadores pré-socráticos, faz operar nas séries de A lógica do sentido. Essas figuras flutuantes são as formas apresentadas pelos simulacros, as quais considera máquinas de "eterno retorno" ${ }^{44}$. Se em

$44 \mathrm{O}$ tema poderia ser desdobrado em ensaio analítico junto ao conceito nietzschiano de "eterno retorno", que em razão de economia desso conjunto não foi explicado. Embora em termos visuais tenha sido desenvolvido pela psicologia analítica de C.G. Jung, o modo como foi usado por Deleuze para mostrar o funcionamento dos simulacros e o próprio acontecimento é o que interessa na presente crítica. Pensar o sentido expresso, junto à produção de séries implicada no arquivo levaria a um trabalho estruturalista, ocupado com proposições de linguagem. Antes de discorrer 
sua fase mais estruturalista Deleuze trata dos escoamentos da fala e o do sem-fundo da linguagem, depois de ser professor reconhecido pela esquizoanálise, pensa a dissipação da Figura na força abstrata produzida pelo movimento em diagrama e na sensação oferecida pela cor. Em Francis Bacon: a lógica da sensação, livro advindo de um curso sobre pintura, ministrado em $1981^{45}$, mostra o rompimento da figuração iconológica identificada na pintura antiga pelo ritmo do que compreende por Figura. Trata-se de sentir a figura como essa vibração encarnada, capaz de produzir uma nevralgia, uma queda na qual a forma "não é mais essência" e sim "acidente" ocorrido entre planos distintos ${ }^{46}$. Enquanto cor, a quedar sentidos, a Figura não tem mais significações, embora toda sua carga de signos e nomes remetam aos significados iconográficos e iconológicos que sua forma designada contém. Designações são mantidas porque exprimem as forças dos acontecimentos. Refúgio dos pecadores, Consoladora dos aflitos, Nossa Senhora Desatadora de Nós, Nossa Senhora do Bom Despacho, Nossa Senhora da Consolação, da Esperança, do Bom Conselho, da Saudade, da Ajuda, da Divina Providência, da Boa Morte, de bons augúrios para tudo: Viagem, Socorro, Sucesso. A figura de Maria também é designada pelos locais de suas aparições, como Caravaggio, Fátima, Lourdes, La Salete ou do resgate de imagens abandonadas, como nas da histórias de Aparecida e Nossa Senhora da Penha. Medianeira, Auxiliadora, da Paz, dos Anjos. Nossas Senhoras de objetos simbólicos de culto, das Candeias, do Rosário, com todos seus mistérios, da Glória, das Graças, das Dores. Boa Nova, De Nazaré, dando indícios de sua descendência da tribo da David, herdeira da Arca, cuja virgindade era cingida conforme as tradições de Israel. Nossa Senhora da Correia, imagem de devoção ao Santo Cinto, objeto feito relíquia emblemático na iconografia de outras divindades mediterrâneas, como Afrodite, oriunda do Chipre. Sanctorum Omnium, Rainha Virgem dos Apostólos e Profetas, cuja

sobre diversos aspectos de um mesmo arquétipo, trata-se de mostrar as variações que o nonsense propõe dissipar nos esquemas a priori estabelecidos para as figuras.

45 DELEUZE, Gilles. Francis Bacon: a lógica da sensação. Trad. Roberto Machado (coord.). Rio de Janeiro: Jorge Zahar, 2007.

46 DELEUZE, Gilles. Francis Bacon: a lógica da sensação. Trad. Roberto Machado (coord.). Rio de Janeiro: Jorge Zahar, 2007.p135. 
nobreza é conferida nas multidões devotada a seus santuários e imagens. As manifestações transcorrem os séculos, ainda que de diversas formas, dando possibilidades para se buscar desde estatuetas paleolíticas, deusas da antiguidade, Virgens paleocristãs nos mosaicos de Ravena, miniaturas e ícones bizantinos, Madonnas renascentistas, as Nossas Senhoras alegóricas propagadas pelo Barroco, as Virtudes clássicas, e as mulheres enigmáticas, ferozes, mortas e etéreas do Simbolismo. Moreau, Knopff, Beardsley, Blake, Kupka, Kubin e outros artistas da virada dos séculos profanam a iconografia misturando signos sacros com temas demoníacos e satíricos e sexuais numa só composição, mostrando figuras femininas de um modo nunca visto anteriormente. Na riqueza do proliferante desse corpus, Redon, pintor fora de qualquer movimento estruturado, com sua série de nascimentos de Afrodite ou Vênus (fig. 7), oferece elementos para pensarmos as aproximações icônicas entre a mais disseminada de todas as imagens do feminino, a figura de Maria, e as divindades pagãs ligadas ao sexo. Virgem Vênus: as sobreposições não se esgotam. Stella Matutina, Lilium Candidum, Rosa Mística, Domus Aurea, Mater Dei, nomes sacralizados em torno de símbolos arcaicos da Grande Mãe, consorte do próprio filho, irmã de seu marido, esposa do Pai. Maria, enquanto mito sobrepujante na moral higienista da cultura vitoriana, na rígida sociedade que condenou Wilde por seu pensamento livre e sexualidade tomada como "escandalosa", não é a mesma força a quem renderam culto os versos do poeta. A diferença das interpretações e contradição dos usos para qual serve a figura de Nossa Senhora, também chamada na vulgata Mulier Fortis, permite que possamos concluir que em cada corpo ela produz reverberações distintas e subjetivações singulares. A cada revelação um segredo, em cada repetição da imagem, novos sentidos, no contemplar despido de significados morais a pura sensação. Essa Virgo potens (outra de suas invocações) extrapola personagens literários e históricos para se tornar figura de narrativas cambiantes que diluem suas representações na abertura dos devires da arte. Desencontros entre versões de sua história e as inúmeras variações no delineamento de sua imagem mostram as infinitas possibilidades de criação do feminino. Figura axial na representação da feminilidade, pela liberdade com a qual cantam dentro dos versos, a Virgem Mãe atesta o quanto a expressão 
sempre incerta da linguagem impede de fechar sobre uma forma representativa as forças encerradas no mito.

\section{Figura 7}

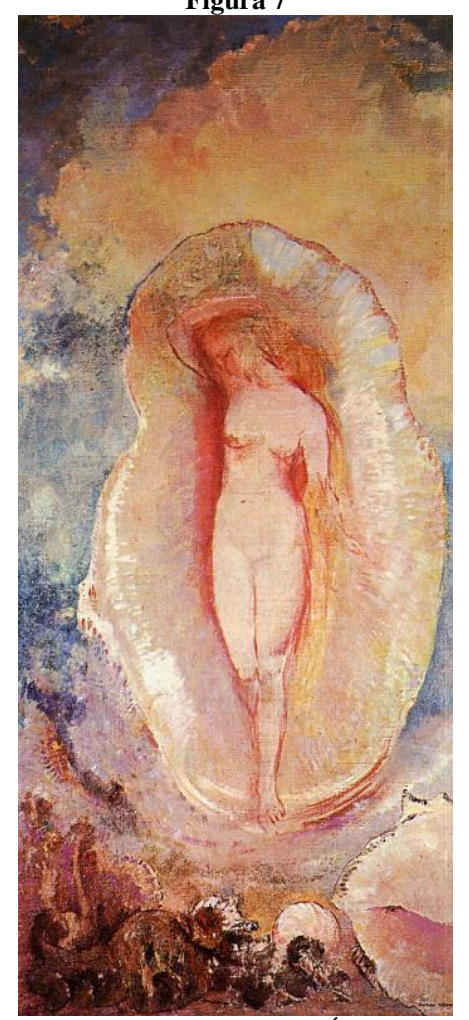

Odilon Redon, La Naissance de Vénus, 1912. Óleo sobre tela, 143,2×62,5 cm. Coleção Stephen Higgons, Moma, NY. Disponível em http://www.wikiart.org/en/odilon-redon/the-birth-of-venus-1912-1\#supersizedartistPaintings-247971, acesso em março de 2015.

RECEBIDO EM: 17/06/2016 APROVADO EM: 06/06/2017 